\title{
Research on the Classification of the Advanced Manufacturing Mode Qinghui Dai ${ }^{1,}$, , Hongmei $\mathrm{Li}^{1, \mathrm{~b}}$ \\ ${ }^{1}$ Department of Mechanical Engineering, North China Electric Power University, Baoding, Hebei, 071000, China \\ adcba6789@126.com, b15933981096@163.com
}

Keywords: Manufacturing mode, Advanced manufacturing mode, Types, Classification.

\begin{abstract}
This paper presents a classification approach for advanced manufacturing mode (AMM). Firstly the concept and features of the advanced manufacturing mode are expounded in the paper. Then the advanced manufacturing modes are divided from three aspects: the manufacturing mode development concept, the manufacturing process variability and the business mode. The content and manufacturing method of each types of manufacturing mode are analyzed; and the features of each manufacturing method under three types of manufacturing mode are compared. Based on the analysis and research, this paper provides a reference for the enterprises to choose the suitable manufacturing mode in the actual production process.
\end{abstract}

\section{Introduction}

Manufacturing mode is a mode referring to the enterprise system, operation, management, production organization, technology system configuration and operation, which is a focus of research both in China and abroad. The enterprises have to improve operation and management methods to ensure the effectiveness of the production due to unpredictable changes of market. Agile manufacturing, flexible manufacturing, lean production, and other advanced manufacturing modes emerge in an endless stream, which makes the enterprises feel puzzled. Researchers and experts never stop the study of the advanced manufacturing mode, while there's very few studies on classification. This paper analyzes various advanced manufacturing modes, and presents a classification approach for advanced manufacturing mode.

\section{Concept of AMM}

Definition of AMM. Mode is a standard form of something or a standard style that person can refer to. Manufacturing mode is a production pattern driven by demand and technology to promote and enable manufacturers to produce a breakthrough change of production [1]. The objective of each manufacturing mode is driven by the market, the change of social demand and the introduction of new technologies. The general model of manufacturing mode is shown in Fig. 1. The advanced manufacturing model refers to a kind of advanced methods of similar characteristics, which applied to manufacturing system, and is a way of application of advanced manufacturing technology of production organization and technology system configuration and operation [2].

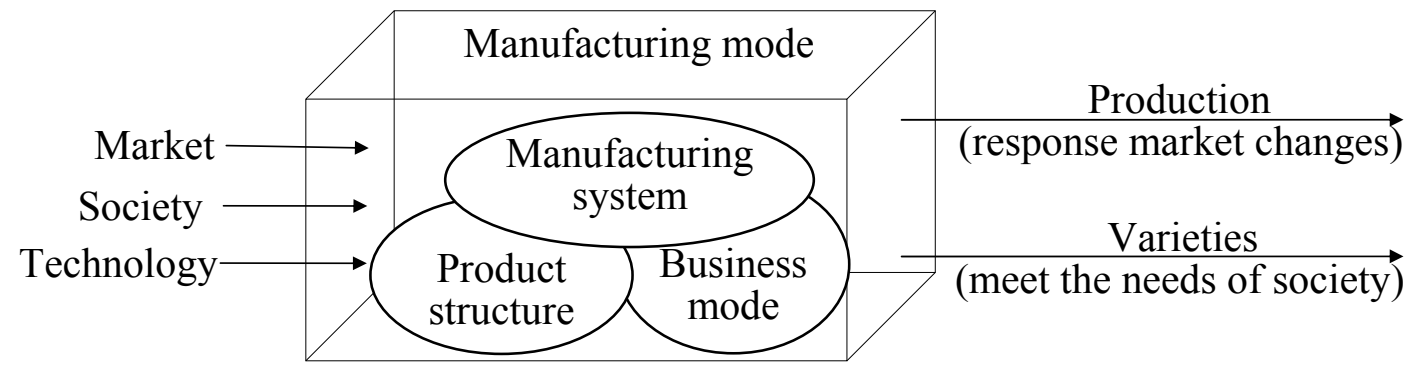

Fig. 1 The model of manufacturing mode 
Characteristics of AMM. The types of AMM are large, but all have three common characteristics: obtaining access to productive effectiveness, rapid and effective integration of resources and the combination of people, organization and technology. Enterprises will quickly choose the correct model type by learning the characteristics of AMM.

(1) Obtaining access to productive effectiveness. The primary goal of AMM is to response to unpredictable market changes rapidly to satisfy the business enterprise production efficiency. AMM puts production effectiveness at the first place, and makes changes of manufacturing value orientation, strategic priorities, basic principles, guiding ideology.

(2) Rapid and effective integration of resources. The basic principle of AMM is integrating resources rapidly and effectively in larger space and deeper level to improve the strain capacity of the enterprise by enhancing the consistency of the manufacturing system and flexibility.

(3) The combination of people, organization and technology. The guiding of AMM is human-centered [3]. Implementation approach of AMM is the combination of people-organizationtechnology to ensure the effectiveness of the production. The three essential resources are people, organization, and technology.

\section{Classification of AMM}

According to the statistics of International Production Engineering Society in recent 10 years, the developed countries have sprung up to 33 kinds of advanced manufacturing mode, and there are 17 kinds of typical AMM at present. The advanced manufacturing modes are divided from three aspects: the manufacturing mode development concept, the manufacturing process variability and the business mode. Manufacturing mode development concept emphasizes the thoughts and ideas of enterprise manufacturing; manufacturing process variability concentrates on the change of the manufacturing process; business mode is classified by the view of strategic planning point based on the relationship of information flow and logistics. The classification results are as follows:

Divided According to the Manufacturing Mode Development Concept. From the thought idea, the development trend of advanced manufacturing mode can be divided into two aspects: values and the system, shown in Fig. 2.

1) From the perspective of values, the development trend of manufacturing mode has two directions: humanization manufacturing and benefit manufacturing. Humanization manufacturing mode directly serves the participant's physical and mental needs related to the product, emphasizing the potential of participants; However, the benefit manufacturing mode directly serves to all aspects of the product manufacturing process, emphasizing the working efficiency of the participants and resource utilization.

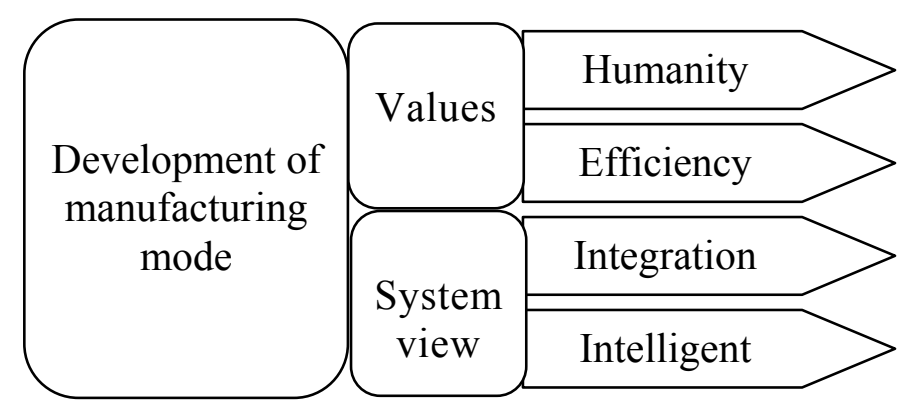

Fig. 2 Development of manufacturing mode

2) From the perspective of system, the development trend of manufacturing mode has two directions: Integrated manufacturing and intelligent manufacturing. Integrated manufacturing mode is widely used of Computer Integrated Manufacturing (CIM) and Agile Manufacture (AM), based on computer network and database. Intelligent manufacturing mode is the result of the AI technology, emphasizing the integration of information and knowledge.

Division According to the Manufacturing Process Variability. Process variability refers to the change of manufacturing process. According to it, the manufacturing mode can be divided into three: 
(1) Dedicated Manufacturing Mode (almost no process variability); (2) Flexible Manufacturing Mode (process variability a little); (3) Reconfigurable Manufacturing Mode (process variability a bigger).

1) Dedicated Manufacturing Mode (DMM). Based on dedicated machine tool, dedicated manufacturing system (DMS) uses special production line, and the layout of processing and assembly workstations is in a straight line. But each workstation only can complete the immutable task. 2) Flexible Manufacturing Mode (FMM). The system is composed of programmable computer numerical control machine tools and robots, and can produce new products by changing parts of the processing procedures and fixtures, which is easy to be variable. 3) Reconfigurable Manufacturing Mode (RMM). The reconfigurable manufacturing system (RMS), which is a system combined of computer numerical control machine tools and Reconfigurable Machine Tool (RMT), is designed according to the capacity and function, and can quickly respond to market changes without influences to the overall robustness and reliability. The comparison of three kinds of manufacturing system is shown in Table 1.

Table 1 Comparison of DMM, FMM and RMM

\begin{tabular}{c|c|c|c}
\hline & $\begin{array}{c}\text { Dedicated } \\
\text { manufacturing }\end{array}$ & Flexible manufacturing & $\begin{array}{c}\text { Reconfigurable } \\
\text { manufacturing }\end{array}$ \\
\hline $\begin{array}{c}\text { Product } \\
\text { characteristics }\end{array}$ & $\begin{array}{c}\text { A single species of } \\
\text { mass production }\end{array}$ & $\begin{array}{c}\text { Many species of small } \\
\text { production }\end{array}$ & $\begin{array}{c}\text { Many varieties of variable } \\
\text { production }\end{array}$ \\
\hline Customizability & Almost no & Medium & Large \\
\hline System structure & Fixed & Convertible & Convertible \\
\hline Process variability & Almost no & A little & Large \\
\hline Capacity & High & Low & High \\
\hline Life-cycle cost & Low & Reasonable & Medium \\
\hline
\end{tabular}

Divided According to the Business Mode. The advanced manufacturing mode can be divided into three kinds: push mode, pull mode, push-pull mode. This pattern is advantageous for the enterprise management, and is divided according to the relationship between information flow and logistics. It do have a certain enterprise management level.

As the information flow and logistics are in the same direction, the order of driving push mode is: design $\rightarrow$ production $\rightarrow$ sales, such as mass production and information manufacturing mode; However, pull mode is contrary to push mode. The order of pull mode business is: sales $\rightarrow$ design $\rightarrow$ production, such as lean production, manual production, global manufacturing mode [4]; Push-pull mode refers to the combinations of push mode (design and production) and pull mode (assembly production options), and the order is: design $\rightarrow$ sales $\rightarrow$ production, such as mass customization mode. Characteristics of four kinds of typical manufacturing mode are shown in Table 2.

Table 2 Characteristics of four kinds of typical manufacturing mode

\begin{tabular}{c|c|c|c|c}
\hline $\begin{array}{c}\text { Manufacturin } \\
\text { g mode }\end{array}$ & $\begin{array}{c}\text { Manual } \\
\text { production }\end{array}$ & $\begin{array}{c}\text { Mass } \\
\text { production }\end{array}$ & $\begin{array}{c}\text { Mass } \\
\text { customization }\end{array}$ & Global manufacturing \\
\hline Goal of MM & $\begin{array}{c}\text { Meet customer } \\
\text { requirements }\end{array}$ & $\begin{array}{c}\text { Reduce the } \\
\text { product cost }\end{array}$ & $\begin{array}{c}\text { Many varieties, } \\
\text { high quality }\end{array}$ & A quick response \\
\hline $\begin{array}{c}\text { New demand } \\
\text { of society }\end{array}$ & $\begin{array}{c}\text { Design of } \\
\text { single product }\end{array}$ & $\begin{array}{c}\text { Low cost } \\
\text { products }\end{array}$ & $\begin{array}{c}\text { Many kinds of } \\
\text { high quality } \\
\text { products }\end{array}$ & $\begin{array}{c}\text { Fast delivery, the } \\
\text { regional, personalized } \\
\text { products }\end{array}$ \\
\hline $\begin{array}{c}\text { Pulling power } \\
\text { of market }\end{array}$ & $\begin{array}{c}\text { Unstable } \\
\text { demand }\end{array}$ & Stable demand & Stable demand & Unstable demand \\
\hline $\begin{array}{c}\text { Force of } \\
\text { technical }\end{array}$ & Electric power & $\begin{array}{c}\text { Interchangeable } \\
\text { parts }\end{array}$ & Computer & $\begin{array}{c}\text { Information technology } \\
\text { and the Internet }\end{array}$ \\
\hline $\begin{array}{c}\text { Principle of } \\
\text { business mode }\end{array}$ & Pull mode & Push mode & Push-pull mode & Pull mode \\
\hline
\end{tabular}

1) Manual production of pull mode. Manual production is the original form of industrial production, and engages in production activities by using manual labor or simple tools [5]. 
2) Mass production of push mode. Mass production refers to produce the same kind of great bulk product at one time. The typical mode is manufacturing resource planning (MRP II) and enterprise resource planning (ERP).

3) Mass customization of push-pull mode. MC is a mode driven by the social demand for more products, and oriented by customer demand.

4) Global manufacturing mode of pull mode. Global manufacturing mode must adopt a special kind of pull business mode, and there are two trends of it: (1) regional production; (2) personalized production.

AMM can be divided from multiple aspects. In this paper, the advanced manufacturing modes are divided from three aspects: the thought idea, manufacturing process and business strategy. It is useful for the scholars' further study and helpful for enterprises to distinguish the differences to combine its market competition environment and strategic. Manufacturing is not only the foundation and means of imagination, conception, the science, and the technology of material change, but also the expression of national economy, national defense, and the support industries [6]. Manufacturing enterprises must be clear that AMM may play an important role only when the competition environment, enterprise strategy adapt to it.

\section{Conclusions}

Through the classification of three aspects: the thought idea, manufacturing process and business mode, it clearly compared the differences between manufacturing mode types. AMM will develop sustainable and rapidly in the future. With the development of market competition and the progress of science and technology, the advanced manufacturing mode types will also be more and more. Enterprises must take appropriate advanced manufacturing mode according to their actual situation; only in this way can they develop steady and rapidly.

\section{References}

[1] Yoram Koren, in: The Global Manufacturing Revolution, edtied by Jun Ni, Jingxi Chen Publications/Machinery Industry Press, Beijing (2014), in press.

[2] Qinghui Dai: Advanced Manufacturing System (Machinery Industry Press, Beijing 2008).

[3] Xiaolan Wang: Consume Guide No. 2 (2008), p. 166. In Chinese.

[4] Li Zhen, Pingyu Jiang, Lihong Qiao, Lifeng Xi: Journal of Mechanical Engineering No. 21 (2010), p. 134. In Chinese.

[5] Xiuqin S, Xiwei L, Gang X, Changjian C, Yonghong Ma, Timo R. Nyberg: 2013 IEEE International Conference on Service Operations and Logistics, and Informatics, Dongguan, 2013. p. 220

[6] Xiankui Wang: Frontiers of Mechanical Engineering in China. Vol. 2(3) (2007), p. 251 